\title{
Experimental Study to Determine the Failure Criteria of Concrete at Its Early-Age
}

\author{
Hongyan Ding, ${ }^{1,2,3}$ Lei Zhang, ${ }^{3}$ and Puyang Zhang ${ }^{1,2,3}$ \\ ${ }^{1}$ State Key Laboratory of Hydraulic Engineering Simulation and Safety, Tianjin University, Tianjin 300072, China \\ ${ }^{2}$ Key Laboratory of Coast Civil Structure Safety (Tianjin University), Ministry of Education, Tianjin 300072, China \\ ${ }^{3}$ School of Civil Engineering, Tianjin University, Tianjin 300072, China \\ Correspondence should be addressed to Puyang Zhang; zpy_td@163.com
}

Received 15 July 2015; Revised 30 October 2015; Accepted 1 November 2015

Academic Editor: Claudio Borri

Copyright (C) 2015 Hongyan Ding et al. This is an open access article distributed under the Creative Commons Attribution License, which permits unrestricted use, distribution, and reproduction in any medium, provided the original work is properly cited.

\begin{abstract}
The failure criteria and the constitutive relation of materials for an early-age concrete are the most common reasons to conduct the nonlinear analysis and to assess the concrete structures during the construction stage. The delay of theoretical advancement in this field resulted into a mismatch between the rough theories and the advanced algorithms, which were adopted for the estimation and analysis of early-age concrete structures. It is often impossible to find an appropriate way to determine the failure criteria and its constitutive relation that may serve as a baseline. As a consequence, the development and the application of advanced techniques of construction, for example, early dismantling construction technique of formwork, have severely been restrained. Therefore, the study of the failure criteria and its constitutive relation of concrete materials at early-age are important. In this paper, the cubic compressive strength, the prismatic compressive strength, and the axial tensile strength are determined by carrying out a strength test on C20 concrete material at an early-age. Next, the failure criteria of C20 early-age concrete material in the octahedral stress space have been studied and analyzed by using the regression analysis and by deriving the mathematical relation.
\end{abstract}

\section{Introduction}

Background of the Project. The cost of formwork for in situ concrete structures in China accounts for approximately $20 \% \sim 30 \%$ of the project cost. How to reduce this cost component in civil works is a key challenge to date. This reduction can lead to completing a project in lower cost. The early dismantling formwork from floor can effectively accelerate the formwork recycling and reduce the construction cost, which is among the "ten new techniques in the building industry" energetically promoted by the Ministry of Housing and Urban-Rural Development of the People's Republic of China. This new technique is extensively being evaluated in China.

In accordance with China's Concrete Construction Quality Acceptance Code for Acceptance of Concrete Structure Quality (GB50204-2002), the criteria for the removal of formwork from concrete floor have been shown in Table 1.

The following inferences can be drawn from the code: (1) in case the formwork span is $l \leq 2 \mathrm{~m}$, the underside formwork can be removed when the concrete strength has reached up to $50 \%$ of the standard value of the designed cubic compressive strength of the concrete; (2) in case the formwork spans are $2 \mathrm{~m}<l \leq 8 \mathrm{~m}$ and $l>8 \mathrm{~m}$, the underside formwork can be removed when the concrete strength has, respectively, reached up to $75 \%$ and $100 \%$ of the standard value of the designed cubic compressive strength of the concrete.

During the construction process while keeping in view the above code, large-span floors can be divided into more than one temporary and supporting spans to turn them into floors each having span less than $2 \mathrm{~m}$. This provision allows us to remove the underside formwork, when the concrete strength has reached up to $50 \%$ of the standard value of the designed cubic compressive strength of the concrete. To conclude, the cost of formwork can be saved in engineering projects by simply using new techniques in which the span of structural member is reduced.

During the construction, the formwork of in situ floor is removed in two different phases. The first time is to dismantle 
TABLE 1: Minimum requirements of concrete strength for the removal of underside formwork.

\begin{tabular}{lcc}
\hline Structural member type & $\begin{array}{c}\text { Structural member span }(\mathrm{m}) \\
\text { Formwork }\end{array}$ & $\begin{array}{c}\text { Percentage of the standard value of the designed cubic compressive } \\
\text { strength of the concrete }(\%)\end{array}$ \\
\hline & $>2, \leq 8$ & $\geq 50$ \\
& $>8$ & $\geq 75$ \\
Beam, arch, and shell & $\leq 8$ & $\geq 100$ \\
\hline Cantilever member & $>8$ & $\geq 100$ \\
\hline
\end{tabular}

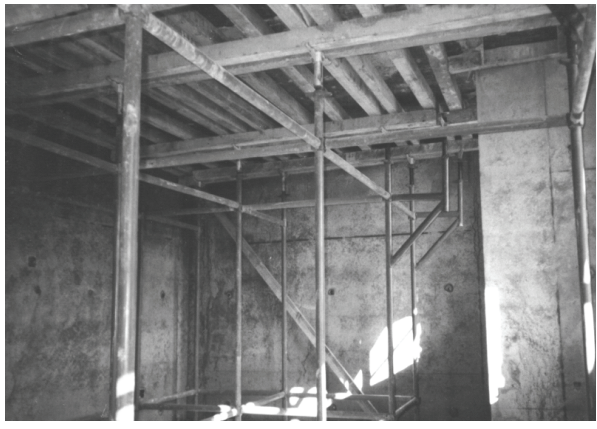

(a)

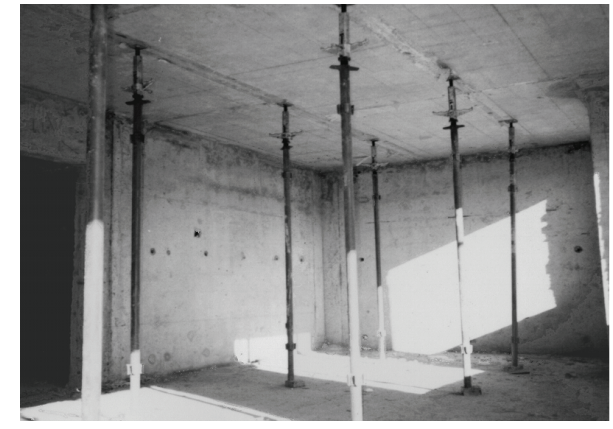

(b)

FIGURE 1: The comparison of vertical formwork supporting system. (a) shows the complete erection of formwork. (b) shows the concrete floor immediately after the first removal of formwork. This early removal technique is adopted from the early dismantling technique of construction.

the formwork partially and retain part of the formwork supports; the second time step is to dismantle the rest of the formwork when the floor structure has met the requirements on complete dismantling. The comparison of the vertical formwork supporting system has been shown in Figure 1.

Under the given situation that there are no uniform standards and acceptable specifications for the early dismantling formwork construction technique of the formworks in China, Beijing Construction Engineering Group, Tianjin University, and many other scientific research institutions have started the work to compile the technical code for the early dismantling construction of formworks. This code is meant to provide regulations, criteria, and guidance regarding the design, construction, organizational management, early dismantling formwork, and so on.

The research group, supervised by Professor Hongyan Ding from Tianjin University, undertook the structural analysis and experimental studies of the aforementioned code [1]. To provide a theoretical base for this project, a series of experimental studies have been conducted for the failure criteria and for determining the constitutive relation of the early-age concrete materials under biaxial stress.

Introduction of the Related Theories. A major problem of the early dismantling formwork is lack of related failure criteria and assessment methods of the concrete at an earlyage, so the successful implementation of the work has been delayed. The failure criteria and the constitutive relation of materials may provide the mathematical relation to describe the material characteristics [2,3]. However, there are no uniform rules of the failure criteria and the constitutive relation for ordinary concrete materials, which have been researched for decades $[2,3]$. Thus, on the basis of study of the strength and deformation tests, the failure criteria and the constitutive relation of concrete materials constitute the basics theoretical development of both the nonlinear analysis of concrete structures and the development of structural design. The failure criteria of an early-age concrete lay the theoretical foundation of the construction technique of the early dismantling formwork $[1,4,5]$. Since there was not enough work carried out in this field, there is still a mismatch between the rough models and the advanced algorithms, as these have been adopted for the analysis of early-age concrete structures. It is often impossible to find the appropriate criteria of failure and the constitutive relation, which may serve as a baseline. Thus, studying the failure criteria and the constitutive relation of early-age concrete materials are important from practical and theoretical points of view.

Until now, many researchers have proposed the hundreds of criteria for the concrete failure [6-8], of which the classical theories of strength and their blueprint were derived on the basis of the geometrical shape of the surface of envelope, whereas other theories are purely based on mathematical models. The original equations of the aforementioned failure criteria have been adopted at different levels of stresses; their mathematical patterns and the levels of difficulty differ from 
each other. As a consequence, they contained significant differences from each other in terms of the applicable scope and the assessment accuracy. In the existing literature [8], the theoretical values for the various common criteria of failure were assessed; the domestic and the foreign multiaxial strength data were analyzed and compared; and each criteria of failure was evaluated, which may be adopted as a reference in further applications [9]. The space-based failure criteria of concrete at the multiaxial stress state can be classified into the following categories: (1) the theoretical models with one parameter, that is, the maximum tensile stress theory as it has been proposed by Rankine and the shear stress theory as it has been proposed by Tresca and Misis; (2) the theoretical models with two parameters, that is, the theories proposed by MohrCoulomb and Drucker-Prager, which fall within the scope of theories describing early failure criteria $[2,6]$ and play an important role in promoting and developing the theories of concrete strength, notwithstanding differing significantly from the complex actual failure envelope surface of concrete; some of which are still being extensively applied today by virtue of the simplicity of their expression and the convenience of hand calculation; and (3) the theoretical models with multiple parameters, as these have been developed by developing the test techniques as well as analytical theories and by compiling the criteria of concrete failure in the recent time, that is, the three-parameter theoretical model, as it has been proposed by Boris and Pister [10] and William and Warnke [11], the four-parameter theoretical model, as it has been proposed by Ottosen [12] and Hsieh et al. [13, 14], and the five-parameter theoretical model, as it has been proposed by Tsinghua University [6], Podgórski [15], and Dalian University of Technology [16]. Of which, the research development of Tsinghua University has been incorporated into the code for design of concrete structures (GB500102002) [17]. Currently, there are many theories that are being developed, for example, the twin theory of shear strength [18], the theory of crack friction [19], the theory of fracture mechanics [20,21], and the theory of fractal geometry [22]. The space-based failure criteria of strain is classified into the following two types: (1) those which are transformed from the space-based failure criteria of stress, for example, the theoretical model as it has been proposed by Romstad et al. [23]; and (2) those which are directly established on the basis of test materials, for example, the theoretical models featured by linear and nonlinear relations between the principal strain and the shear strain [21]. It is relatively difficult to obtain the accurate strain data for the multiaxial test of concrete. It is pertinent to mention that the strain data have extremely high discreteness; and these are available for a very few reliable theoretical models of space-based failure criteria of strain. Thus, research of space-based failure criteria of strain is still at a preliminary stage, which cannot be used for practical purposes.

On the basis of a study of the failure criteria of an ordinary concrete, researchers have carried out the tests of biaxial strength and deformation characteristics of the steel-fiber reinforced concrete [24], the flexible concrete [25, $26]$, the reactive powder concrete $[27,28]$, the lightweight aggregate concrete $[29,30]$, and the concrete of aggregate gradation [31]. The associated biaxial criteria of failure were established at the same time, when the rules of their strength were analyzed. Many researchers carried out the tests of biaxial compression-compression and the biaxial tensioncompression on an ordinary concrete [32], an air-entrained concrete [33], and a lightweight aggregate concrete [34] during the freezing and the thawing cycles and the spacebased failure criteria of strain. The above types of concrete materials were established after taking into account the differences in the number of freezing and thawing cycles and the compression-compression and tension-compression stress ratios.

In this paper, the concrete with a designed strength grade of C20 was mainly selected to perform the experimental study to determine the failure criteria of an early-age concrete. "C20 concrete material at an early-age" was adopted to represent "concrete material at an early-age with a designed strength grade of C20."

\section{Description of Tests}

In this paper, an experimental study has been performed to study the strength and the deformation characteristics of C20 concrete samples at an early-age for four special states of stresses, which can be assumed as accurate and easy to realize, that is, the uniaxial compression, the uniaxial tension, the biaxial compression, and the uniaxial compression-tension (refer to Table 2).

The concrete composition, as employed in this paper, was designed with reference to the New Query Manual of Concrete Strength Design and Composition [35] (refer to Table 3).

According to the specifications, all test samples were required to be cured. In the curing room, the temperature was maintained between 8 and $15^{\circ} \mathrm{C}$; the humidity was maintained between 30 and $50 \%$. The test samples were not allowed to be stacked up; they were required to be spread out flatly at the floor by keeping a clear spacing of approximately $20 \mathrm{~mm}$. The seven different age-groups were set for testing, that is, one day, two days, three days, four days, five days, six days, and seven days. During the test, the delay in the process of curing was not allowed to exceed beyond $30 \mathrm{~min}$.

\section{Test Results}

On the basis of the tests, as these have been provided in Table 1, the results of C20 concrete at an early-age of standard curing were measured (refer to Table 4).

\section{Derivation for the Failure Criteria of Concrete at an Early-Age}

4.1. Failure Criteria. The conditions of failure criteria can be described as the material under investigation has reached either to the state of failure or to the state of ultimate strength during the loading process; that is, the failure criteria of the material may provide the mathematical relation describing the surface of failure envelope in a stress space, as it has 
TABLE 2: Description of different experimental studies.

\begin{tabular}{|c|c|c|c|}
\hline Test type & Size of test sample & Test method & Aim of test \\
\hline Compressive strength & $\begin{array}{c}150 \mathrm{~mm} \times 150 \mathrm{~mm} \times 150 \mathrm{~mm} \\
\text { cube }\end{array}$ & \multirow{5}{*}{$\begin{array}{l}\text { Chinese standard } \\
\text { GB/T50081-2002 }\end{array}$} & $\begin{array}{l}\text { To determine the value of cubic } \\
\text { compressive strength }\end{array}$ \\
\hline $\begin{array}{l}\text { Uniaxial compressive strength and } \\
\text { deformation characteristic }\end{array}$ & $\begin{array}{c}40 \mathrm{~mm} \times \underset{\text { prism }}{40 \mathrm{~mm}} \times 160 \mathrm{~mm} \\
\text {. }\end{array}$ & & $\begin{array}{l}\text { To determine the value of prismatic } \\
\text { compressive strength }\end{array}$ \\
\hline Uniaxial tensile strength & $\begin{array}{c}150 \mathrm{~mm} \times 150 \mathrm{~mm} \times 300 \mathrm{~mm} \\
\text { prism }\end{array}$ & & $\begin{array}{l}\text { To determine the value of axial } \\
\text { tensile strength }\end{array}$ \\
\hline $\begin{array}{l}\text { Biaxial compressive-compressive strength } \\
\text { and deformation characteristic }\end{array}$ & $\begin{array}{c}40 \mathrm{~mm} \times \underset{\text { prism }}{40 \mathrm{~mm}} \times 160 \mathrm{~mm} \\
\text {. }\end{array}$ & & $\begin{array}{l}\text { To determine the value of biaxial } \\
\text { compressive-compressive strength }\end{array}$ \\
\hline Biaxial tensile-compressive strength & $\begin{array}{c}150 \mathrm{~mm} \times 150 \mathrm{~mm} \times 300 \mathrm{~mm} \\
\text { prism }\end{array}$ & & $\begin{array}{l}\text { To determine the value of biaxial } \\
\text { tensile-compressive strength }\end{array}$ \\
\hline
\end{tabular}

TABLE 3: The concrete composition and the material consumption.

\begin{tabular}{lccccc}
\hline Cement type & $\begin{array}{c}\text { Fine aggregate } \\
\text { class }\end{array}$ & $\begin{array}{c}\text { Size of coarse } \\
\text { aggregate }(\mathrm{mm})\end{array}$ & Mixing water & Slump $(\mathrm{mm})$ & Composition ratio \\
\hline 425 Portland cement & Medium sand & Grain size $\leq 25$ & Tap water & $30-50$ & $\begin{array}{c}\text { [Cement : sand : stone: water] }= \\
{[1: 1.59: 3.38: 0.54]}\end{array}$ \\
\hline
\end{tabular}

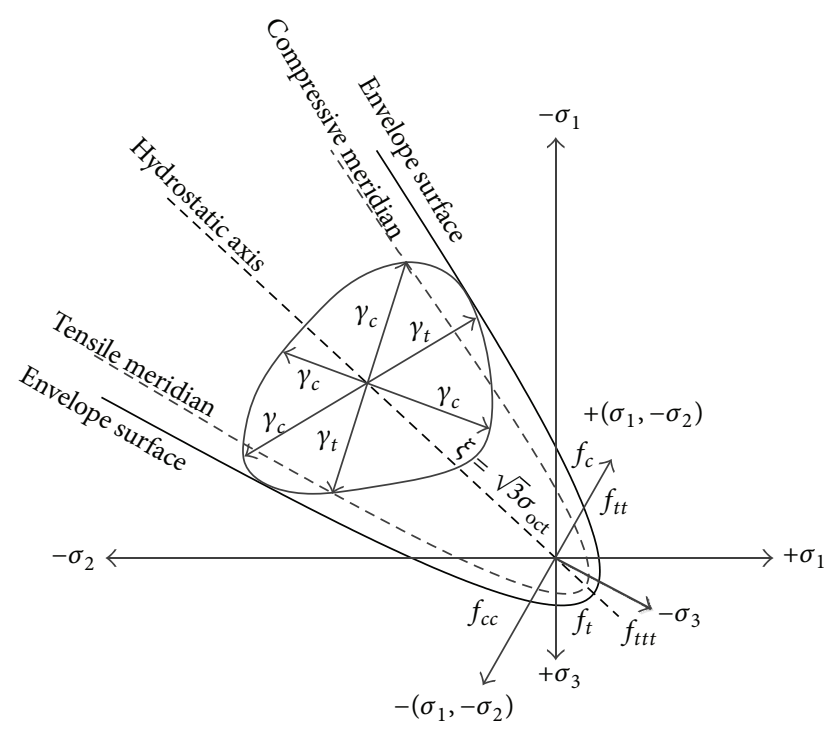

FIGURE 2: The failure envelope for the surface of concrete [9].

been shown in Figure 2. The failure criteria of an ordinary concrete can generally be established in accordance with the octahedral stress space. This paper introduces the octahedral stress space to establishing the criteria of failure and yield for C20 concrete at an early-age.

On the basis of delineating the multiaxial strength data $\left(f_{1}, f_{2}, f_{3}\right)$ of concrete, as it has been obtained during the test in space (i.e., the coordinates of principal stress $\left(\sigma_{1}, \sigma_{2}, \sigma_{3}\right)$ ) and by connecting the various adjacent points of test in a smooth surface, the test-based surface of failure envelope of concrete can thus be obtained, as it has been shown in Figure 1. It can also be expressed by using the cylindrical coordinates $\left(\sigma_{\text {oct }}, \tau_{\text {oct }}, \theta\right)$ in accordance with the following relations of conversion:

$$
\begin{aligned}
\sigma_{\mathrm{oct}} & =\frac{1}{3}\left(f_{1}+f_{2}+f_{3}\right), \\
\tau_{\mathrm{oct}} & =\frac{1}{3} \sqrt{\left(f_{1}-f_{2}\right)^{2}+\left(f_{2}-f_{3}\right)^{2}+\left(f_{3}-f_{1}\right)^{2}}, \\
\theta & =\arccos \left(\frac{2 f_{1}-f_{2}-f_{3}}{3 \sqrt{2} \tau_{\mathrm{oct}}}\right) .
\end{aligned}
$$

The criteria of failure can mathematically be expressed by following the coordinates $\left(\sigma_{\text {oct }}, \tau_{\text {oct }}, \theta\right)$ of the octahedral stress space as

$$
F\left(\sigma_{\text {oct }}, \tau_{\text {oct }}, \theta\right)=0
$$

where $F$ is the failure function, the specific mathematical expression, which can be obtained from the surface of failure envelope, as it has been established in accordance with the strength data at the complex stress state.

On the basis of elastic-plastic mechanics, we can assume the following relations among the $\left[\sigma_{\text {oct }}, \tau_{\text {oct }}, \theta\right]$, the first stress 


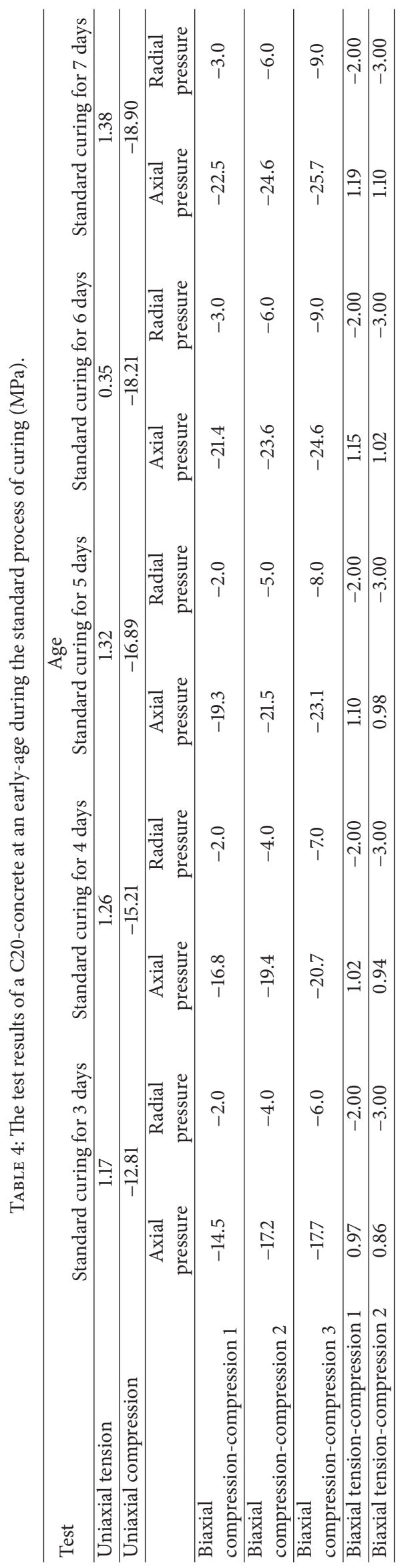


TABLE 5: The values of normal stress and the shear stress in an octahedral stress space for the ultimate strength of a C20 concrete at an early-age $(\mathrm{MPa})$.

\begin{tabular}{|c|c|c|c|c|c|c|c|c|c|c|}
\hline \multirow{3}{*}{ Test } & \multicolumn{10}{|c|}{ Age } \\
\hline & \multicolumn{2}{|c|}{$\begin{array}{l}\text { Standard curing } \\
\text { for } 3 \text { days }\end{array}$} & \multicolumn{2}{|c|}{$\begin{array}{l}\text { Standard curing } \\
\text { for } 4 \text { days }\end{array}$} & \multicolumn{2}{|c|}{$\begin{array}{l}\text { Standard curing } \\
\text { for } 5 \text { days }\end{array}$} & \multicolumn{2}{|c|}{$\begin{array}{l}\text { Standard curing } \\
\text { for } 6 \text { days }\end{array}$} & \multicolumn{2}{|c|}{$\begin{array}{l}\text { Standard curing } \\
\text { for } 7 \text { days }\end{array}$} \\
\hline & $\sigma_{\text {oct }}$ & $\tau_{\text {oct }}$ & $\sigma_{\text {oct }}$ & $\tau_{\text {oct }}$ & $\sigma_{\text {oct }}$ & $\tau_{\text {oct }}$ & $\sigma_{\text {oct }}$ & $\tau_{\text {oct }}$ & $\sigma_{\text {oct }}$ & $\tau_{\text {oct }}$ \\
\hline Uniaxial tension & 0.39 & 0.56 & 0.42 & 0.59 & 0.44 & 0.62 & 0.45 & 0.64 & 0.46 & 0.65 \\
\hline Biaxial tension-compression 1 & -0.34 & 1.24 & -0.32 & 1.25 & -0.30 & 1.28 & -0.28 & 1.30 & -0.27 & 1.32 \\
\hline Biaxial tension-compression 2 & -0.71 & 1.65 & -0.69 & 1.68 & -0.67 & 1.69 & -0.66 & 1.71 & -0.63 & 1.73 \\
\hline Uniaxial compression & -4.27 & 6.03 & -5.07 & 7.16 & -5.63 & 7.97 & -6.07 & 8.58 & -6.30 & 9.00 \\
\hline Biaxial compression-compression 1 & -5.50 & 6.42 & -6.27 & 7.49 & -7.10 & 8.66 & -8.13 & 9.46 & -8.50 & 9.97 \\
\hline Biaxial compression-compression 2 & -7.07 & 7.35 & -7.80 & 8.36 & -8.83 & 9.18 & -9.87 & 10.0 & -10.2 & 10.5 \\
\hline Biaxial compression-compression 3 & -7.90 & 7.35 & -9.23 & 8.59 & -10.3 & 9.58 & -11.2 & 10.2 & -11.6 & 10.6 \\
\hline
\end{tabular}

tensor invariant $I_{1}$, the second deviator stress tensor $J_{2}$, and the third deviator stress tensor $J_{2}$ :

$$
\begin{aligned}
\sigma_{\text {oct }} & =\frac{1}{3} I_{1}, \\
\tau_{\text {oct }} & =\sqrt{\frac{2}{3} J_{2},} \\
\theta & =\frac{1}{3} \cos ^{-1} \frac{3 \sqrt{3}}{2} \frac{J_{3}}{J_{2}^{2 / 3}},
\end{aligned}
$$

where $\theta \in[0, \pi / 3]$.

By substituting (5) (7) into the failure criteria, as it has been expressed by (4), we can obtain the failure criteria by the following stress invariants $I_{1}, J_{2}$, and $J_{3}$ :

$$
F\left(I_{1}, J_{2}, J_{3}\right)=0 \text {. }
$$

4.2. Failure Criteria of an Early-Age Concrete. In an octahedral stress space, the failure function $(F)$ is the function of the octahedral normal stress $\left(\sigma_{\text {oct }}\right)$ and the shear stress $\left(\tau_{\text {oct }}\right)$, as it has been shown in the following equation:

$$
F\left(\sigma_{\text {oct }}, \tau_{\text {oct }}\right)=0
$$

4.2.1. The Conversion of Coordinates for Strength Values. By assuming $\left(f_{1} \geq f_{2} \geq f_{3}\right)$ in an octahedral stress space, the strength values $\left(f_{1}, f_{2}, f_{3}\right)$ of the tests can be converted into the normal stress value $\left(\sigma_{\text {oct }}\right)$ and the shear stress value $\left(\tau_{\text {oct }}\right)$. The conversion of coordinate for the strength can be achieved by using (1) and (2) (refer to Table 5).

4.2.2. Determining the Failure Criteria. The results of the normal stress $\sigma_{\text {oct }}$ and the shear stress $\tau_{\text {oct }}$ are provided in an octahedral stress space (refer to Table 4).

The following inferences can be drawn on the basis of research [32]: (1) the failure criteria of a lightweight aggregate concrete at the biaxial and triaxial stress states can be established, and (2) the mathematical expression of the failure criteria of C20 concrete at an early-age can be expressed in the form of a piecewise function, as it has been shown in Figure 3.

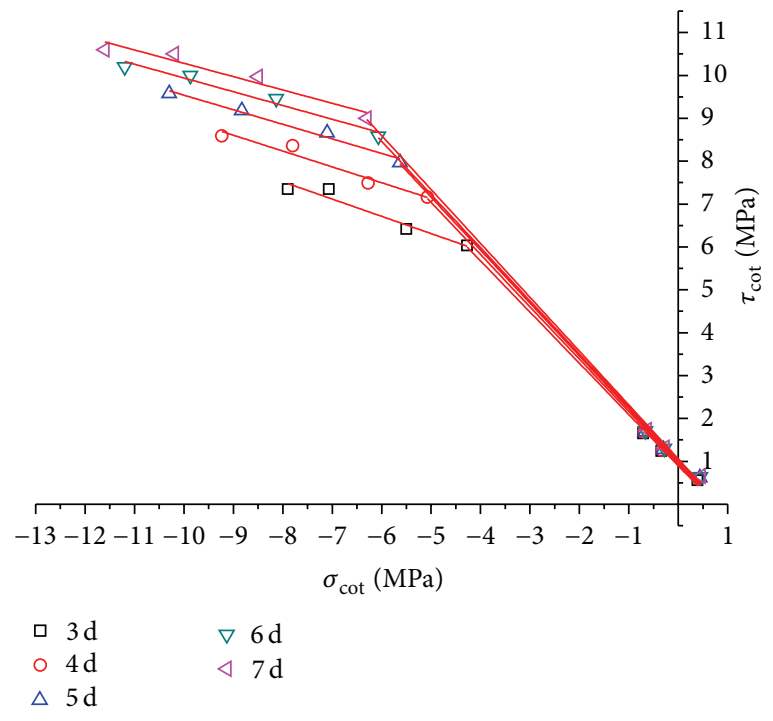

FIgURE 3: An octahedral normal stress and shear stress for the ultimate strength of $\mathrm{C} 20$-concrete at an early-age after standard duration of curing, that is, 3-7 days.

As it can be inferred from Figure 2, the coordinate values for the various points of uniaxial compressive strength of concrete in an octahedral stress space are apparently the "inflection points," which are situated at the line for all of the strength coordinates of concrete with the same types of curing type and age. Thus, by first substituting the uniaxial compressive strength point (i.e., $\left.\left(0,0,-f_{c}\right)\right)$ of concrete into (1) and (2), the following mathematical relations can be obtained:

$$
\begin{aligned}
\sigma_{\mathrm{oct}, c} & =-\frac{1}{3} f_{c}, \\
\tau_{\mathrm{oct}, c} & =\frac{\sqrt{2}}{3} f_{c}, \\
\frac{\tau_{\mathrm{oct}, c}}{\sigma_{\mathrm{oct}, c}} & =-\sqrt{2} .
\end{aligned}
$$


The values of $\left(\tau_{\text {oct }, c} / \sigma_{\text {oct }, c}\right)$ in the $\sigma_{\text {oct }}-\tau_{\text {oct }}$ coordinate system are constant, as these have been shown in (12). To ensure that the aforementioned failure criteria, which have been established for the concrete materials of different types of curing and ages, contain the uniform forms of definition that can easily be compared. The straight line, which passes through the origin of coordinates, can be selected, as it has a slope for the equation of $\left(\tau_{\text {oct }, c} / \sigma_{\text {oct }, c}\right)$ into the $\sigma_{\text {oct }}{ }^{-} \tau_{\text {oct }}$ coordinate system that can be taken as the reference line of the coordinate system. The resulting equation can mathematically be expressed as follows:

$$
\tau_{\text {oct }}+\sqrt{2} \sigma_{\text {oct }}=0 .
$$

Similarly by substituting the point of uniaxial tensile strength $\left(f_{t}, 0,0\right)$ into (1) and (2), we obtain

$$
\begin{aligned}
\sigma_{\mathrm{oct}, t} & =\frac{1}{3} f_{t}, \\
\tau_{\mathrm{oct}, t} & =\frac{\sqrt{2}}{3} f_{t}, \\
\frac{\tau_{\mathrm{oct}, t}}{\sigma_{\mathrm{oct}, t}} & =\sqrt{2} .
\end{aligned}
$$

As it can be observed from (16), the all values of $\left(\tau_{\text {oct }, t} / \sigma_{\text {oct }, t}\right)$ into the $\sigma_{\text {oct }}{ }^{-} \tau_{\text {oct }}$ coordinate system are constant. The straight line which passes through the origin of coordinates can be selected, which has a slope for the equation of $\left(\tau_{\text {oct }, t} / \sigma_{\text {oct } t,}\right)$ into the $\sigma_{\text {oct }}-\tau_{\text {oct }}$ coordinate system as a reference line of the coordinate system; the resulting equation can mathematically be expressed as follows:

$$
\tau_{\text {oct }}-\sqrt{2} \sigma_{\text {oct }}=0 .
$$

On the basis of the aforementioned two straight lines of reference and in regard to the characteristics of bifold line of the failure criteria for $\mathrm{C} 20$ concrete during an early-age in an octahedral stress space, the following mathematical relation of its failure criteria can be assumed:

when $\tau_{\text {oct }}+\sqrt{2} \sigma_{\text {oct }} \leq 0$, therefore,

$$
F\left(\sigma_{\text {oct }}, \tau_{\text {oct }}\right)=\tau_{\text {oct }}-M_{1}-N_{1} \sigma_{\text {oct }}=0 ;
$$

when $\tau_{\text {oct }}+\sqrt{2} \sigma_{\text {oct }}>0, \tau_{\text {oct }}-\sqrt{2} \sigma_{\text {oct }} \geq 0$, therefore,

$$
F\left(\sigma_{\text {oct }}, \tau_{\text {oct }}\right)=\tau_{\text {oct }}-M_{2}-N_{2} \sigma_{\text {oct }}=0,
$$

where $M_{1}, N_{1}, M_{2}$, and $N_{2}$ are coefficients that need to be determined.

On the basis of a piecewise functional expression, as it has been assumed by (18) and (19), the mathematical relation of the failure criteria for C20 concrete during an early-age in an octahedral stress space can be solved first by means of a mathematical derivation [7] as follows.

(1) When $\tau_{\text {oct }}+\sqrt{2} \sigma_{\text {oct }} \leq 0$, we can substitute (10) and (11) into (18) and thus obtain

$$
\tau_{\mathrm{oct}, c}-M_{1}-N_{1} \sigma_{\mathrm{oct}, c}=0 .
$$

From (20), we can obtain

$$
M_{1}=\tau_{\text {oct }, c}-N_{1} \sigma_{\text {oct }, c},
$$

where $N_{1}$ represents the slope of the equation of (20), and it can be obtained from the test points through a direct linear fitting; thereafter, it can assess the value of $M_{1}$ by using (21). Next, by substituting the values of $N_{1}$ and $M_{1}$ into (18) simultaneously, we can obtain the mathematical relation of the failure criteria under the condition of $\tau_{\text {oct }}+\sqrt{2} \sigma_{\text {oct }} \leq 0$ as follows.

(2) When $\tau_{\text {oct }}+\sqrt{2} \sigma_{\text {oct }} \geq 0, \tau_{\text {oct }}-\sqrt{2} \sigma_{\text {oct }} \geq 0$, we can substitute (10) and (11) into (19) and, thus, obtain

$$
\tau_{\text {oct }, c}-M_{2}-N_{2} \sigma_{\text {oct }, c}=0 .
$$

Thereafter, by substituting (14) and (15) into (4)-(19), we get

$$
\tau_{\text {oct }, t}-M_{2}-N_{2} \sigma_{\text {oct }, t}=0 .
$$

By synthesizing (4)-(22) and (4)-(23), we can obtain

$$
\begin{aligned}
& M_{2}=\frac{\tau_{\mathrm{oct}, c} \sigma_{\mathrm{oct}, t}-\tau_{\mathrm{oct}, t} \sigma_{\mathrm{oct}, c}}{\sigma_{\mathrm{oct}, t}-\sigma_{\mathrm{oct}, c}}, \\
& N_{2}=\frac{\tau_{\mathrm{oct}, t}-\tau_{\mathrm{oct}, c}}{\sigma_{\mathrm{oct}, t}-\sigma_{\mathrm{oct}, c}} .
\end{aligned}
$$

By substituting (24) into (19), the mathematical relation of the failure criteria under the condition of $\tau_{\text {oct }}+\sqrt{2} \sigma_{\text {oct }} \geq 0$ and $\tau_{\text {oct }}-\sqrt{2} \sigma_{\text {oct }} \geq 0$ can be obtained.

The failure criteria of C20 concrete at an early-age can thus be obtained; that is,

$$
\text { when } \tau_{\text {oct }}+\sqrt{2} \sigma_{\text {oct }} \leq 0 \text {, therefore, }
$$

$$
\begin{aligned}
& F\left(\sigma_{\mathrm{oct}}, \tau_{\mathrm{oct}}\right)=\tau_{\mathrm{oct}}-\tau_{\mathrm{oct}, c}+N_{1}\left(\sigma_{\mathrm{oct}, c}-\sigma_{\mathrm{oct}}\right)=0 ; \\
& \text { when } \tau_{\text {oct }}+\sqrt{2} \sigma_{\text {oct }}>0 \text { and } \tau_{\text {oct }}-\sqrt{2} \sigma_{\text {oct }} \geq 0 \text {, therefore, } \\
& F\left(\sigma_{\mathrm{oct}}, \tau_{\mathrm{oct}}\right)=\tau_{\mathrm{oct}}-\frac{\tau_{\mathrm{oct}, c} \sigma_{\mathrm{oct}, t}-\tau_{\mathrm{oct}, t} \sigma_{\mathrm{oct}, c}}{\sigma_{\mathrm{oct}, t}-\sigma_{\mathrm{oct}, c}} \\
& -\frac{\tau_{\mathrm{oct}, t}-\tau_{\mathrm{oct}, c}}{\sigma_{\mathrm{oct}, t}-\sigma_{\mathrm{oct}, c}} \sigma_{\mathrm{oct}}=0 .
\end{aligned}
$$

By substituting (10) and (11) into (25) and by substituting (10), (11), (14), and (15) into (25) and (26), we obtain the following:

when $\tau_{\text {oct }}+\sqrt{2} \sigma_{\text {oct }} \leq 0$, therefore,

$$
\begin{gathered}
F\left(\sigma_{\text {oct }}, \tau_{\text {oct }}\right)=\tau_{\text {oct }}-\frac{\sqrt{2}}{3} f_{c}-N_{1}\left(\frac{1}{3} f_{c}-\sigma_{\text {oct }}\right)=0 ; \\
\text { when } \tau_{\text {oct }}+\sqrt{2} \sigma_{\text {oct }} \geq 0, \tau_{\text {oct }}-\sqrt{2} \sigma_{\text {oct }} \geq 0 \text {, therefore, }
\end{gathered}
$$

$$
F\left(\sigma_{\mathrm{oct}}, \tau_{\mathrm{oct}}\right)=\tau_{\mathrm{oct}}-\frac{2 \sqrt{2}}{3} \frac{f_{t} f_{c}}{f_{t}+f_{c}}-\sqrt{2} \frac{f_{t}-f_{c}}{f_{t}+f_{c}}=0,
$$


TABLE 6: Biaxial strength formula of the concrete [6].

\begin{tabular}{|c|c|c|c|}
\hline Broken line & Stress state & Stress ratio & Calculation formula \\
\hline $\mathrm{AB}$ & Compression-compression $\left(\sigma_{1}=0\right)$ & $r=\frac{\sigma_{2}}{\sigma_{3}}, \quad 0.2 \leq r \leq 1$ & $f_{3}=-1.2 f_{c}, \quad f_{2}=-1.2 r f_{c}$ \\
\hline $\mathrm{BC}$ & Compression-compression $\left(\sigma_{1}=0\right)$ & $r=\frac{\sigma_{2}}{\sigma_{3}}, \quad 0 \leq r \leq 0.2$ & $f_{3}=\frac{-1.2}{1.2-r} f_{c}$ \\
\hline CD & Tension-tension $\left(\sigma_{2}=0\right)$ & $r=\frac{\sigma_{1}}{\sigma_{3}}, \quad-0.05 \leq r \leq 0$ & $f_{3}=\frac{-1.2}{1.2-r} f_{c}$ \\
\hline $\mathrm{DE}$ & Tension-compression $\left(\sigma_{2}=0\right)$ & $r=\frac{\sigma_{1}}{\sigma_{3}}, \quad r \leq-0.05$ & $f_{3}=\frac{-0.96 f_{t} f_{c}}{f_{t}-(0.048+0.96 r) f_{c}}$ \\
\hline $\mathrm{EF}$ & Tension-tension $\left(\sigma_{3}=0\right)$ & $r=\frac{\sigma_{2}}{\sigma_{1}}, \quad 0 \leq r \leq 1$ & $f_{1}=f_{t}$ \\
\hline
\end{tabular}

where $N_{1}$ can be assessed through a linear fitting of test data after measuring the biaxial compressive strength of concrete, and both the uniaxial compressive strength $\left(f_{c}\right)$ and the uniaxial tensile strength $\left(f_{t}\right)$ can directly be measured during the test.

By substituting (5) and (6), respectively, into (27) and (28), the mathematical relation of the failure criteria, as it has been expressed by the first stress tensor invariant $\left(I_{1}\right)$ and the second deviator stress tensor $\left(J_{2}\right)$, can be obtained:

when $\sqrt{3 J_{2}}+I_{1} \leq 0$, therefore,

$$
F\left(I_{1}, J_{2}\right)=\sqrt{6 J_{2}}-\sqrt{2} f_{c}-N_{1}\left(f_{c}+I_{1}\right)=0 ;
$$

when $\sqrt{3 J_{2}}+I_{1}>0, \sqrt{3 J_{2}}-I_{1} \geq 0$, therefore,

$$
F\left(I_{1}, J_{2}\right)=\sqrt{6 J_{2}}-2 \sqrt{2} \frac{f_{t} f_{c}}{f_{t}+f_{c}}-\sqrt{2} \frac{f_{t}-f_{c}}{f_{t}+f_{c}} I_{1}=0 .
$$

In this paper, the regression analysis and the mathematical derivation are combined to determine the failure criteria of $\mathrm{C} 20$ concrete at an early-age. A regression analysis was performed during the tests of biaxial compressive-compressive and tensile-compressive strength in an octahedral stress space. The resulting mathematical relation of the failure criteria, in the form of a piecewise function, has been established. Thereafter, a relatively accurate and measured point of uniaxial compressive characteristic strength was employed to test the already established mathematical relations of the failure criteria. If the relative error, between the measured value of the point of characteristic strength and the assessed value of the already established mathematical relation of the failure criteria at this point, would be less than $15 \%$ then the failure criteria could be adopted. On the other hand, if it was greater than $15 \%$, then the average relation of the failure criteria and (27) and (28) would be assessed and introduced as a mathematical expression of the failure criteria.

4.2.3. Results of the Failure Criteria. On the basis of the aforementioned methods and their analysis, the failure criteria have been established. The strength data of C20 concrete of various types of curing and ages were employed to establish the failure criteria corresponding to the various conditions of loading (refer to Figure 4).

\section{Establishment of a Biaxial Strength Envelope Diagram}

The biaxial strength envelope diagram of the early-age C20 concrete under biaxial stress has further been established. In accordance with Appendix C.3.2 of China's Code [17] for design of concrete structures, the biaxial strength envelope diagram of the ordinary concrete expressed by the principal stress has been given [6,17], as it has been shown in Figure 2 . The broken lines of the three quadrants, as referred to in Figure 2, represent the biaxial tension-tension, tensioncompression, and compression-compression stress states, respectively. Refer to the formulas of the broken lines, as these have been listed in Table 6 [6].

As it can be observed from the failure criteria of the C20 early-age concrete in the octahedral stress space, the mathematical expressions of the failure criteria of the concrete at biaxial tension-tension and biaxial tension-compression stress states can be written in the form of the linear equation in terms of two unknowns; that is,

$$
\begin{aligned}
& \tau_{\mathrm{oct}}=a \sigma_{\mathrm{oct}}+b, \\
& \tau_{\mathrm{oct}}=c \sigma_{\mathrm{oct}}+d,
\end{aligned}
$$

where $a, b, c$, and $d$ are parameters, the values of which can be determined through the mathematical expressions of the failure criteria of the C20 early-age concrete. Therefore, in case of the biaxial tension-tension stress state $\left(0 \geq \sigma_{2} \geq \sigma_{3}\right)$, we have

$$
\begin{aligned}
& \sigma_{\mathrm{oct}}=\frac{1}{3}\left(\sigma_{2}+\sigma_{3}\right), \\
& \tau_{\mathrm{oct}}=\frac{1}{3} \sqrt{\sigma_{2}^{2}+\left(\sigma_{2}-\sigma_{3}\right)^{2}+\sigma_{3}^{2}} .
\end{aligned}
$$

By substituting (33) and (34) into (31), we obtain

$$
\frac{1}{3} \sqrt{\sigma_{2}^{2}+\left(\sigma_{2}-\sigma_{3}\right)^{2}+\sigma_{3}^{2}}=\frac{a}{3}\left(\sigma_{2}+\sigma_{3}\right)+b .
$$

By solving (35), we get 


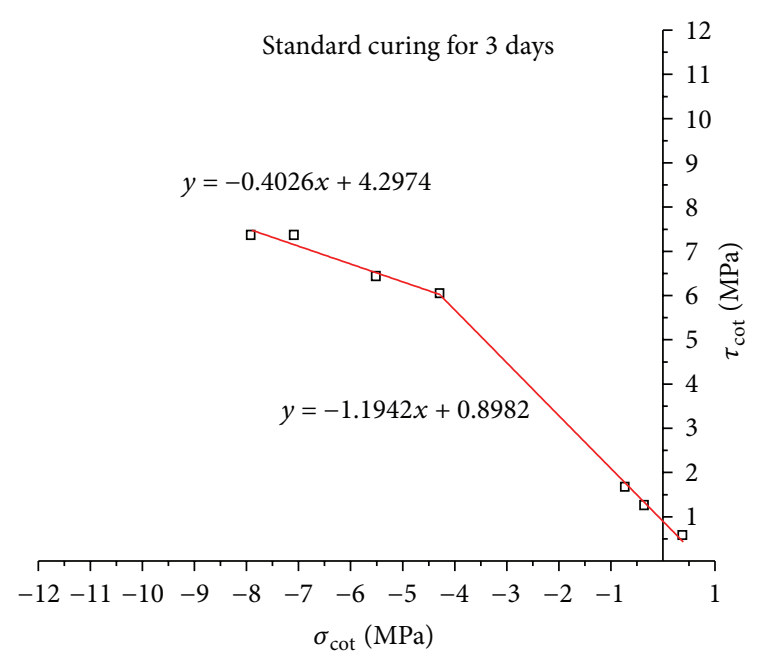

(a)

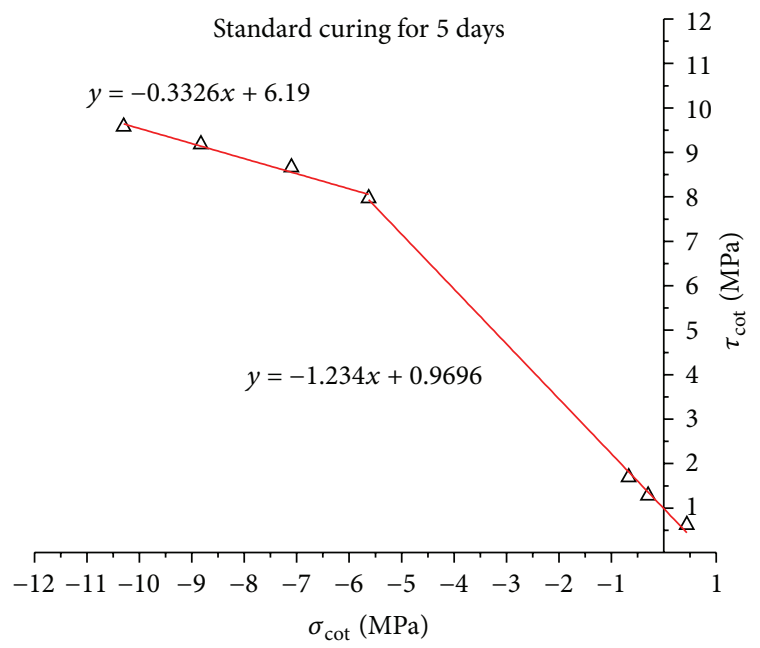

(c)

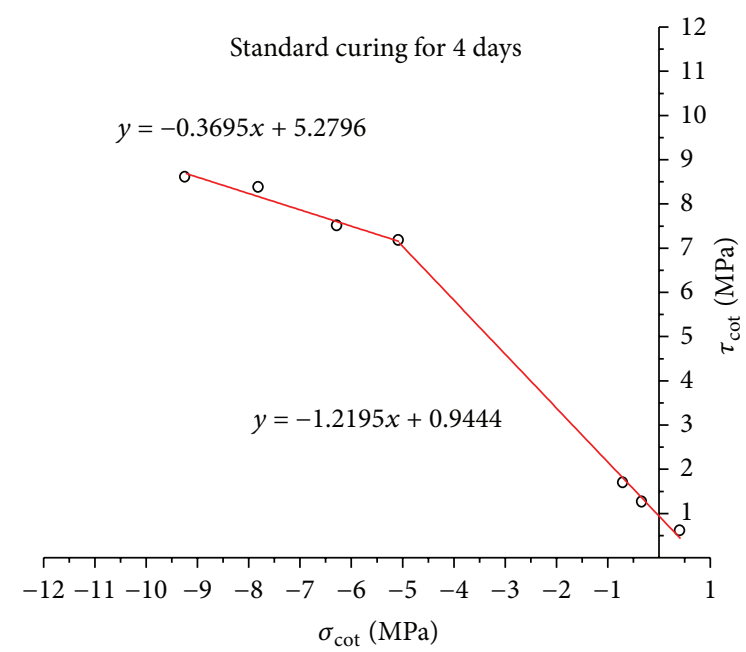

(b)

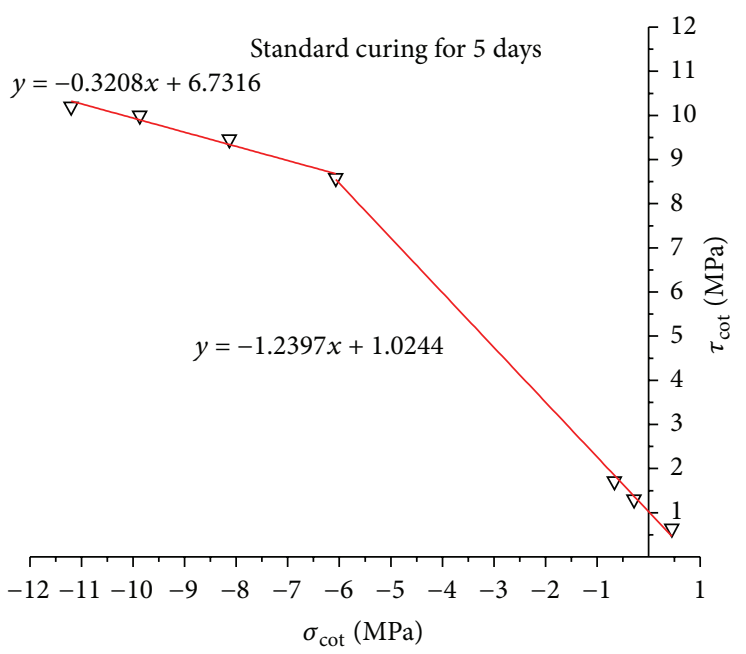

(d)

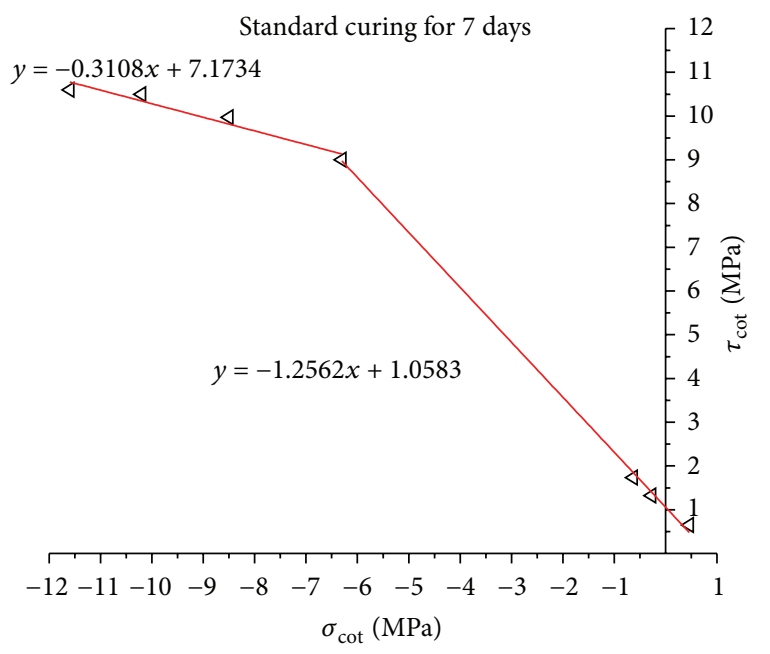

(e)

FIgURE 4: The results of the failure criteria for C20 concrete of various ages during the standard process of curing. 


$$
\begin{aligned}
\sigma_{2}= & \frac{2 \sigma_{3}+2 a^{2} \sigma_{3}+6 a b}{4-2 a^{2}} \\
& \pm\left[\frac{(1 / 4)\left(2 / 9-a^{2} / 9\right)\left(\left(2 \sigma_{3}+2 a^{2} \sigma_{3}+6 a b\right) /\left(2-a^{2}\right)\right)^{2}+\left(a^{2} / 9\right) \sigma_{3}^{2}-(2 / 9) \sigma_{3}^{2}+(2 a b / 3) \sigma_{3}+b^{2}}{2 / 9-a^{2} / 9}\right]^{1 / 2} .
\end{aligned}
$$

With regard to the biaxial tension-compression stress state $\left(\sigma_{1} \geq 0 \geq \sigma_{3}\right)$, we have

$$
\sigma_{\mathrm{oct}}=\frac{1}{3}\left(\sigma_{1}+\sigma_{3}\right)
$$

$$
\begin{aligned}
\sigma_{1}= & \frac{2 \sigma_{3}+2 c^{2} \sigma_{3}+6 c d}{4-2 c^{2}} \\
& \pm\left[\frac{(1 / 4)\left(2 / 9-c^{2} / 9\right)\left(\left(2 \sigma_{3}+2 c^{2} \sigma_{3}+6 c d\right) /\left(2-a^{2}\right)\right)^{2}+\left(c^{2} / 9\right) \sigma_{3}^{2}-(2 / 9) \sigma_{3}^{2}+(2 c d / 3) \sigma_{3}+d^{2}}{2 / 9-c^{2} / 9}\right]^{1 / 2} .
\end{aligned}
$$

$$
\tau_{\mathrm{oct}}=\frac{1}{3} \sqrt{\sigma_{1}^{2}+\sigma_{3}^{2}+\left(\sigma_{3}-\sigma_{1}\right)^{2}} .
$$

By combining (33), (37), and (38), we get
By, respectively, substituting the parameters $a=-0.3108$, $b=7.1734, c=-1.2562$, and $d=1.0583$ of the mathematical expressions of the failure criteria of C20 early-age concrete (after $7 \mathrm{~d}$ of standard curing) into (36) and (39), we can obtain the biaxial ultimate strength envelope diagram of concrete, as it has been shown in Figure 5.

It can be observed from Figure 6 that since ultimate strength envelope diagram of the concrete is symmetrical about the $\sigma_{2} / \sigma_{3}=1$ axial, it is only needed to establish its half-plane biaxial ultimate strength envelope diagram. In accordance with the aforementioned method, the biaxial ultimate strength envelope diagrams of the C20 concrete along with various curing ages have been established. Thereafter, it was compared with the biaxial ultimate strength envelope diagram recommended by the code, as shown in Figures 7-11. The dotted lines in the figures represent the estimated results as obtained by (35) and (38), the solid lines represent the estimated results as recommended by China's national code, and the data points represent the results of biaxial ultimate strength of the concrete measured by the test of this paper.

It can be seen from Figures 7 11 that, when the lateral pressure was relatively small, the values calculated in the test were of good consistency with the values recommended by the code; when the lateral pressure was relatively large, the values calculated in the test were larger than those recommended by the code. When the early-age C20 concrete was under the biaxial tension-compression stress state, the values estimated in the test were slightly lower than the values recommended by the code.

\section{Conclusions}

The build of the failure criterion and the biaxial ultimate strength envelope diagram of the early-age C20 concrete provide a theoretical base for the design and evaluation of the ultimate strength of the early-age C20 concrete materials at biaxial stress state during the project research of the early dismantling formwork construction.

Further, according to the biaxial ultimate strength envelope analysis method for the ordinary concrete used in the literature [6], the biaxial ultimate strength envelope diagram of the early-age C20 concrete was studied and analyzed, and the results show the following:

(1) When the early-age C20 concrete would be at biaxial tension-tension stress state subject to $0<\sigma_{2} / \sigma_{3}<$ $0.35, f_{3}$ could relatively be increased rapidly along with the increase of the stress ratio. In case of $0.35<$ $\sigma_{2} / \sigma_{3}<0.75, f_{3}$ could relatively be increased flat along with a maximum compressive strength value of approximately $(1.50 \sim 1.80) f_{c}$ that may occur in the range of $0.55<\sigma_{2} / \sigma_{3}<0.75$. In case of $0.75<$ $\sigma_{2} / \sigma_{3}<1.0, f_{3}$ could be decreased with the increase of the stress ratio, when a compressive strength of approximately $f_{3}=(1.5 \sim 1.7) f_{c}$ is subject to $\sigma_{2} / \sigma_{3}=$ 1.0 .

(2) When the early-age C20 concrete would be at biaxial tension-compression stress state, the tensile strength $f_{1}$ could decrease with the increase of the principal stress $f_{3}$, and there may be $f_{1} \leq f_{t}$ and $\left|f_{3}\right| \leq f_{c}$ for the biaxial tension-compression strength under any stress ratio $\sigma_{1} / \sigma_{3}$.

\section{Conflict of Interests}

The authors declare that there is no conflict of interests regarding the publication of this paper. 


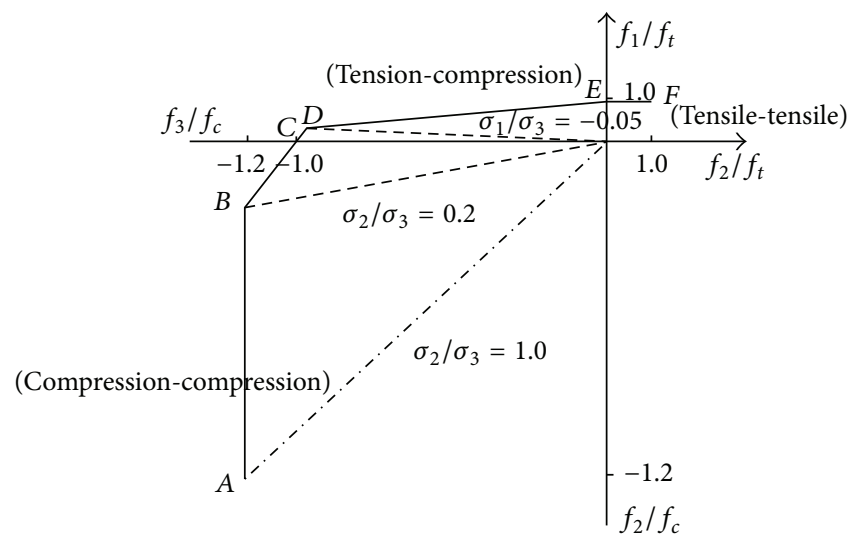

FIGURE 5: Biaxial strength envelope diagram of the concrete [17].

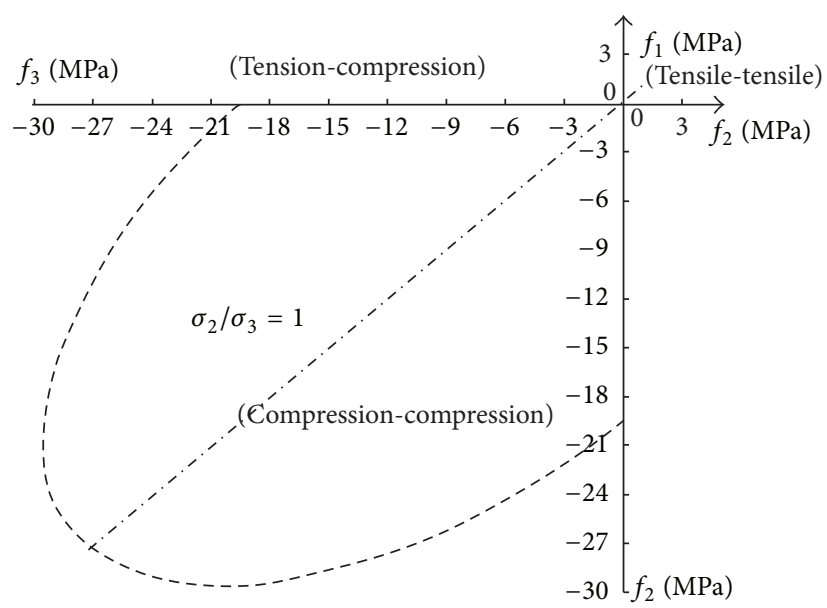

FiguRE 6: Biaxial ultimate strength envelope diagram of C20 concrete after $7 \mathrm{~d}$ of standard curing.

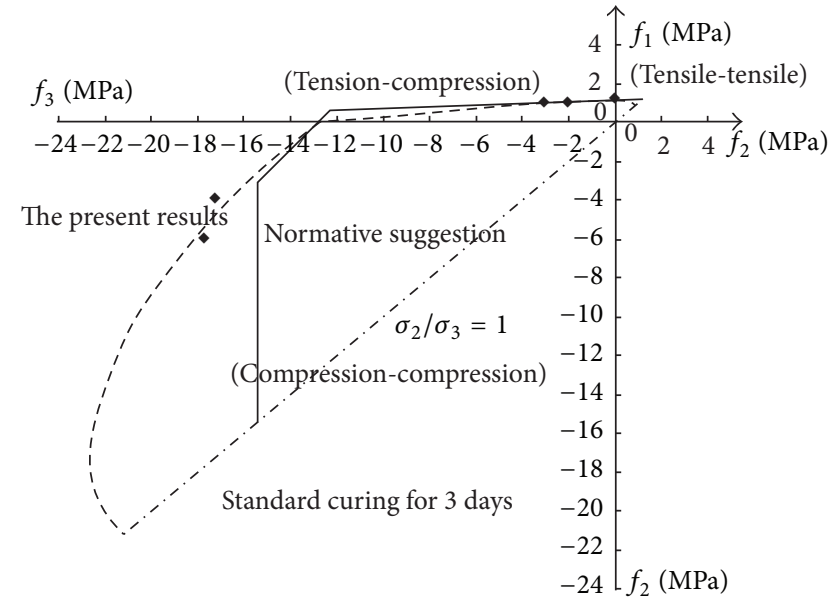

FIgURE 7: Biaxial ultimate strength envelope diagram of the C20 concrete after $3 \mathrm{~d}$ of standard curing.

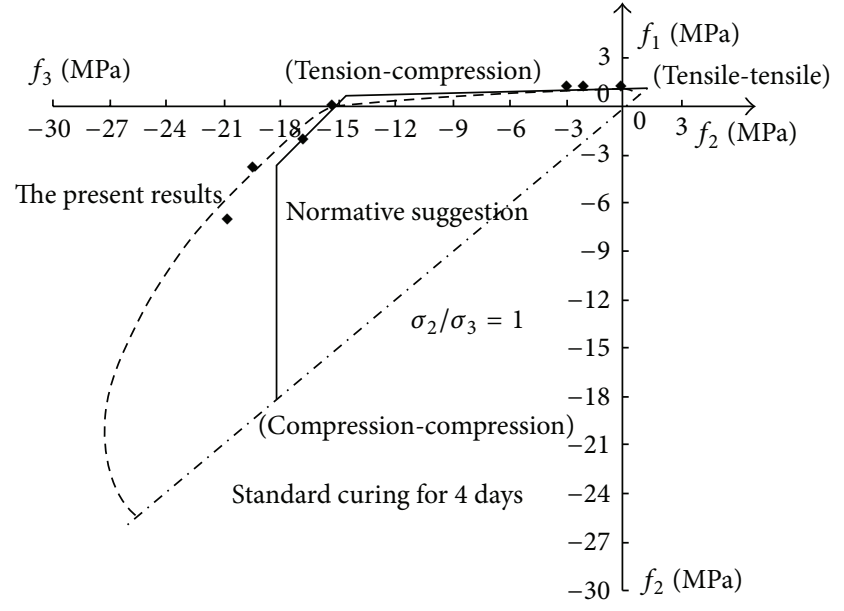

FIGURE 8: Biaxial ultimate strength envelope diagram of the C20 concrete after $4 \mathrm{~d}$ of standard curing. 


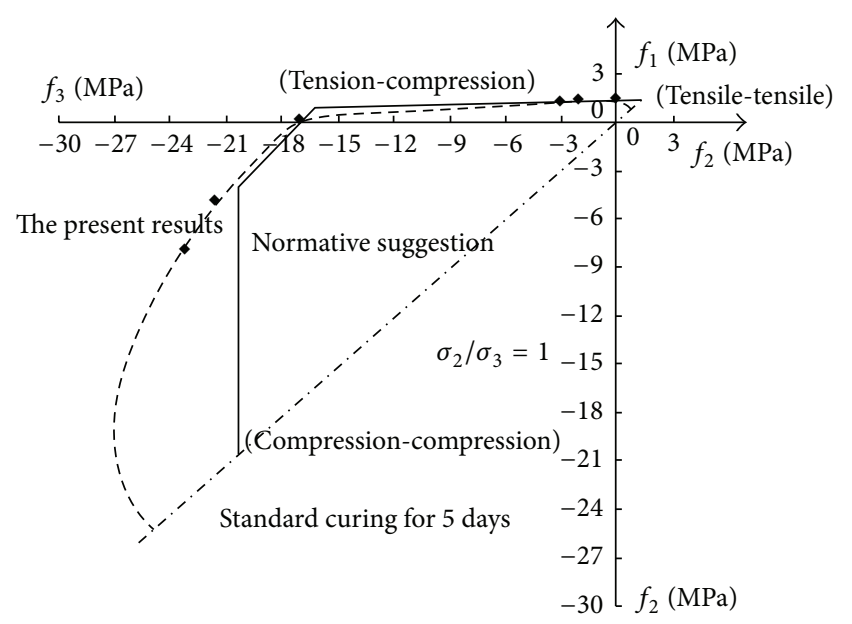

Figure 9: Biaxial ultimate strength envelope diagram of the C20 concrete after $5 \mathrm{~d}$ of standard curing.

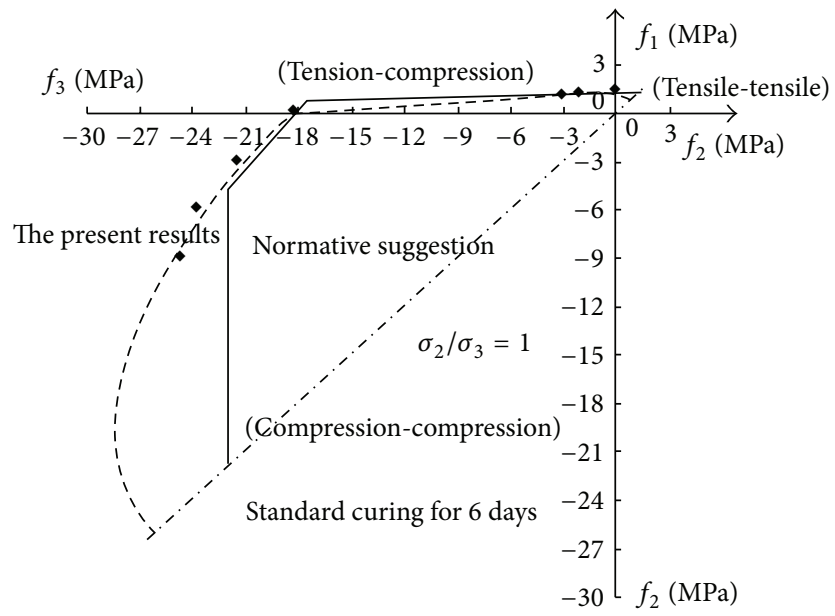

FIGURE 10: Biaxial ultimate strength envelope diagram of the C20 concrete after $6 \mathrm{~d}$ of standard curing.

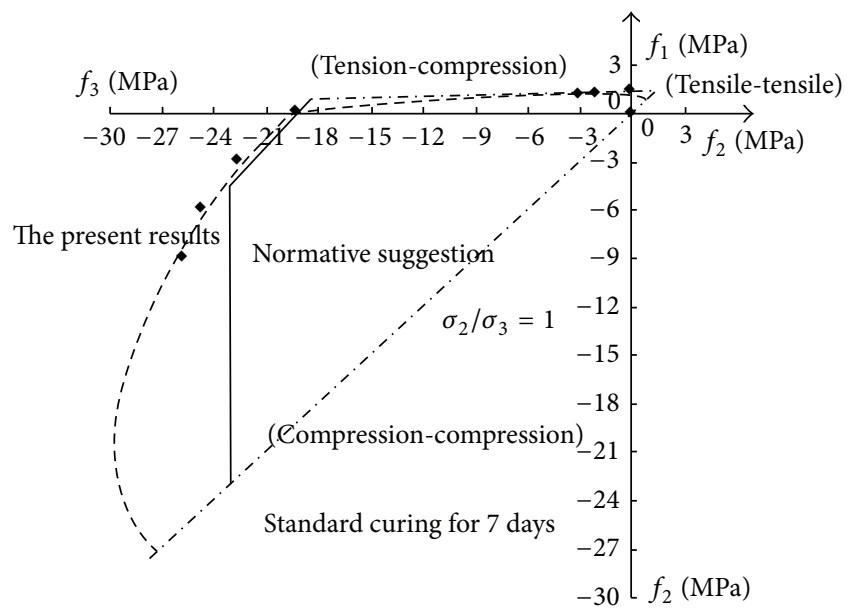

FIGURE 11: Biaxial ultimate strength envelope diagram of the C20 concrete after $7 \mathrm{~d}$ of standard curing.

\section{Acknowledgments}

The authors would like to acknowledge the support from the National Natural Science Foundation of China (Grants nos. 51379142 and 51309179), the Tianjin Municipal Natural Science Foundation (Grants nos. 13JCYBJC19100 and 14JCQNJC07000), and the State Key Laboratory of Hydraulic Engineering Simulation and Safety (Tianjin University) (Grant no. HESS-1302).

\section{References}

[1] H.-Y. Ding, H.-X. Liu, and C. Hou, "Analysis of construction technology for early dismantlement of floor formwork under the least favorable conditions," Journal of Natural Disasters, vol. 18, no. 4, pp. 49-54, 2009.

[2] W.-F. Chen and F. Atef, Constitutive Equations for Engineering Materials: Elasticity and Modeling, vol. 1, Elsevier, 2013.

[3] M. Sargin, Stress-Strain Relationships for Concrete and the Analysis of Structural Concrete Sections, vol. 4, Solid Mechanics Division, University of Waterloo, 1971.

[4] M. K. Hurd, Formwork for Concrete, 1995.

[5] A. M. Jarkas, "The impacts of buildability factors on formwork labour productivity of columns," Journal of Civil Engineering and Management, vol. 16, no. 4, pp. 471-483, 2010.

[6] Z. Guo, Principles of Reinforced Concrete, Butterworth-Heinemann, 2014.

[7] W.-F. Chen, Plasticity in Reinforced Concrete, John Ross Publishing, 2007.

[8] Z. H. Guo, Strength and Deformation of Concrete, Tsinghua University Press, Beijing, China, 1997.

[9] Z. Guo, Strength and Constitutive Relation of Concrete and Its Application, Architecture \& Building Press, Beijing, China, 2004.

[10] B. Boris and K. S. Pister, "Strength of concrete under combined stresses," ACI Journal Proceedings, vol. 55, no. 9, pp. 321-345, 1958.

[11] K. J. William and E. P. Warnke, "Constitutive model for the triaxial behavior of concrete," in Proceedings of the Concrete Structure Subjected to Triaxial Stresses, Bergamo, Italy, 17-19 May 1974, vol. 19, pp. 1-30, International Association for Bridge and Structural Engineering, Zurich, Switzerland, 1975.

[12] N. S. Ottosen, "A failure criterion for concrete," Journal of Engineering Mechanics, vol. 103, no. 4, pp. 527-535, 1977.

[13] S. S. Hsieh, E. C. Ting, and W. F. Chen, "A plastic-fracture model for concrete," International Journal of Solids and Structures, vol. 18, no. 3, pp. 181-197, 1982.

[14] S. S. Hsieh, W. F. Chen, and E. C. Ting, "An elastic-fracture model for concrete," Engineering Mechanics, pp. 437-440, 1979.

[15] J. Podgórski, "General failure criterion for isotropic media," Journal of Engineering Mechanics, vol. 111, no. 2, pp. 188-201, 1985.

[16] S. Yupu and Z. Guofan, "Failure criteria of concrete in strain space," Journal of Dalian University of Technology, vol. 13, no. 4, pp. 455-462, 1991.

[17] Standard Chinese, Code for Design of Concrete Structures (GB 50010-2002), Beijing, China, 2002.

[18] M.-H. Yu, L.-N. He, and L.-Y. Song, "Twin shear stress theory and its generalization," Scientia Sinica Series A-Mathematical, Physical, Astronomical and Technical Sciences, vol. 28, pp. 11741183, 1985. 
[19] Z. P. Bažant and B. H. Oh, "Crack band theory for fracture of concrete," Matériaux et Constructions, vol. 16, no. 3, pp. 155-177, 1983.

[20] R. J. Sanford, Principles of Fracture Mechanics, Pearson College Division, 2003.

[21] B. L. Karihaloo, Fracture Mechanics \& Structural Concrete (Concrete Design \& Construction Series), 1995.

[22] M. Borri-Brunetto, A. Carpinteri, and B. Chiaia, "Scaling phenomena due to fractal contact in concrete and rock fractures," International Journal of Fracture, vol. 95, no. 1-4, pp. 221-238, 1999.

[23] K. M. Romstad, M. A. Taylor, and L. R. Herrmann, "Numerical biaxial characterization for concrete," Journal of the Engineering Mechanics Division, vol. 100, no. 5, pp. 935-948, 1974.

[24] M. C. Nataraja, N. Dhang, and A. P. Gupta, "Stress-strain curves for steel-fiber reinforced concrete under compression," Cement and Concrete Composites, vol. 21, no. 5-6, pp. 383-390, 1999.

[25] M. E. Shartzer Jr., "Flexible concrete form," U.S. Patent No. 6,021,994. 8, 2000.

[26] R. Q. Crow and D. H. Hansen, "Flexible concrete for soil erosion prevention,” U.S. Patent no. 4,375,928, March 1983.

[27] P. Richard and M. Cheyrezy, "Composition of reactive powder concretes," Cement and Concrete Research, vol. 25, no. 7, pp. 1501-1511, 1995.

[28] M. Cheyrezy, V. Maret, and L. Frouin, "Microstructural analysis of RPC (reactive powder concrete)," Cement and Concrete Research, vol. 25, no. 7, pp. 1491-1500, 1995.

[29] J. L. Clarke, Ed., Structural Lightweight Aggregate Concrete, CRC Press, 2002.

[30] A. Short and W. Kinniburgh, Lightweight Concrete, CR books, 1963.

[31] P. H. Bischoff and S. H. Perry, "Compressive behaviour of concrete at high strain rates," Materials and Structures, vol. 24, no. 6, pp. 425-450, 1991.

[32] H. S. Shang and Y. P. Song, "Experimental study of strength and deformation of plain concrete under biaxial compression after freezing and thawing cycles," Cement and Concrete Research, vol. 36, no. 10, pp. 1857-1864, 2006.

[33] H.-S. Shang and Y.-P. Song, "Behavior of air-entrained concrete under the compression with constant confined stress after freeze-thaw cycles," Cement and Concrete Composites, vol. 30, no. 9, pp. 854-860, 2008.

[34] M. B. Karakoç, R. Demirboa, I. Türkmen, and I. Can, "Modeling with ANN and effect of pumice aggregate and air entrainment on the freeze-thaw durabilities of HSC," Construction and Building Materials, vol. 25, no. 11, pp. 4241-4249, 2011.

[35] M. Yao, L. Li et al., Handbook of Concrete Design forStrength, Hunan Science \& Technology Press, Hunan, China, 2000. 

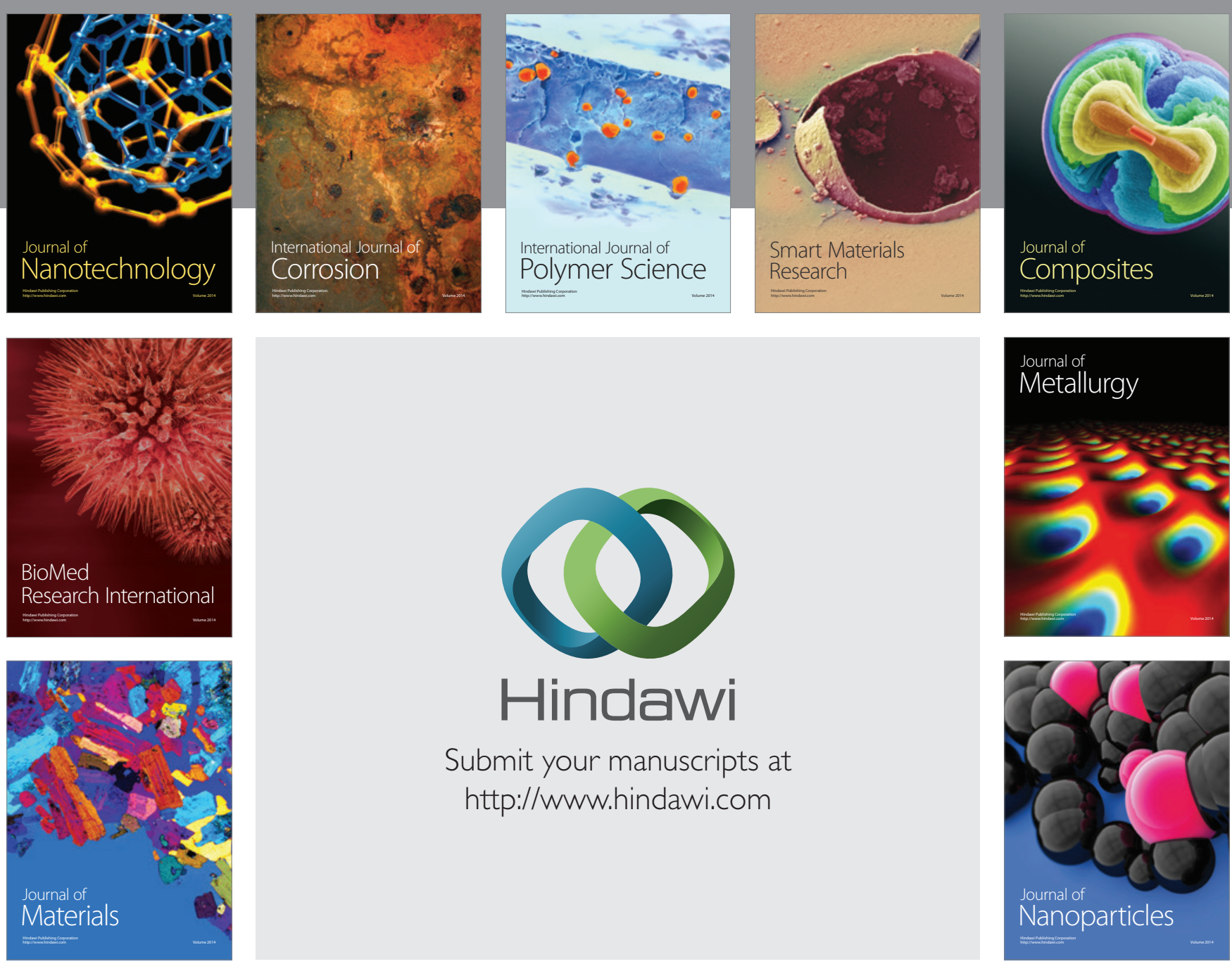

Submit your manuscripts at http://www.hindawi.com
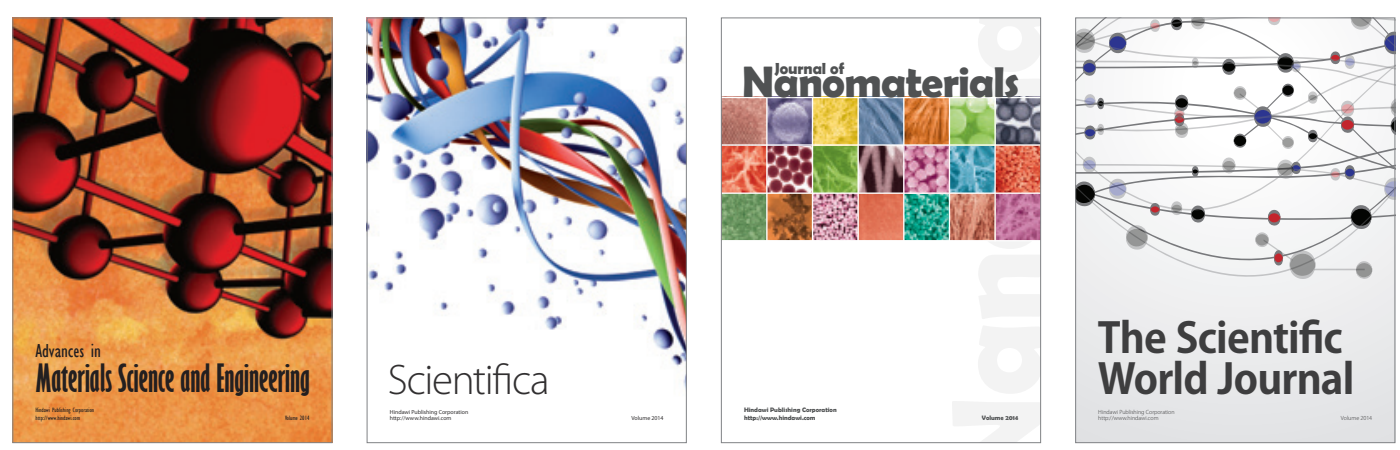

\section{The Scientific World Journal}
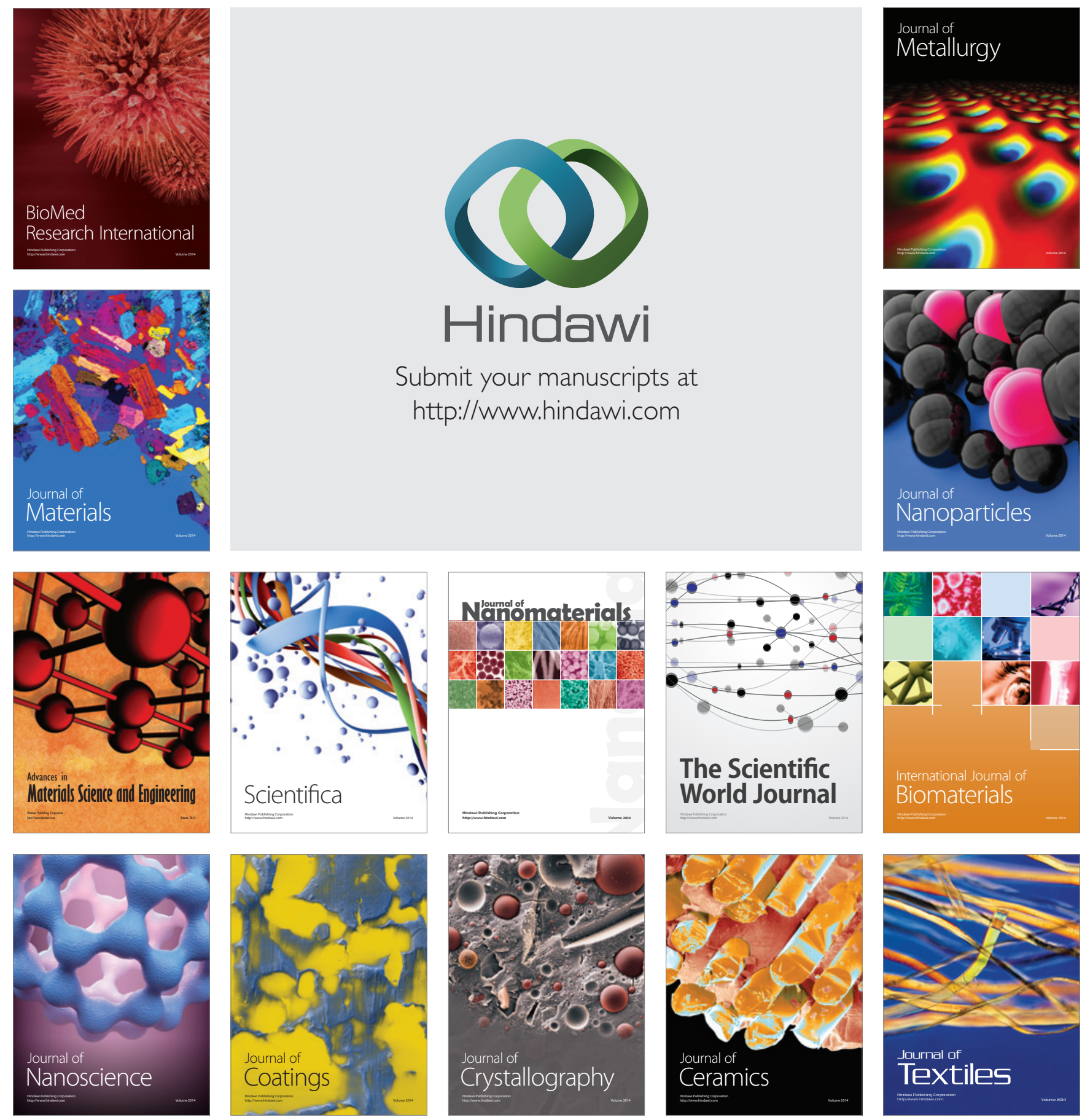